\title{
Rabbit Hepatitis E Virus Infections in Humans, France
}

\section{Florence Abravanel, Sébastien Lhomme, Hicham El Costa, Betoul Schvartz, Jean-Marie Peron, Nassim Kamar, Jacques Izopet}

Hepatitis E virus (HEV) has been detected in rabbits, but whether rabbit HEV strains can be transmitted to humans is not known. Of $919 \mathrm{HEV}$-infected patients in France during 2015-2016, five were infected with a rabbit HEV strain. None of the patients had direct contact with rabbits, suggesting foodborne or waterborne infections.

$\mathrm{R}$ eports of hepatitis E virus (HEV) infections in humans and animals are becoming more frequent. HEV is a member of the family Hepeviridae. HEV strains that infect humans (HEV1, HEV2, HEV3, HEV4, and HEV7) belong to the genus Orthohepevirus (1). In industrialized countries, HEV transmission is mainly zoonotic, and the most prevalent genotype is HEV3. This genotype is transmitted mainly by direct contact with infected pigs, eating contaminated food products, or the environment (2). Genotype 3 includes 3 clades, 2 (3-efg and 3-abchij) of which are found in humans and pigs and 1 (3-ra) of which is found in rabbits (3). HEV3-ra has a 93-nt insertion in the X domain of the genome (4). This virus has been identified in both farmed and wild rabbits worldwide (4) and a pet rabbit (5).

HEV3 infections are generally asymptomatic and selflimiting, but symptomatic acute hepatitis develops in some patients, mostly older men. Fulminant hepatitis can occur in patients with underlying liver disease, and HEV3 infections can become chronic in immunocompromised patients, such as recipients of solid-organ transplants, persons with hematologic diseases, and patients infected with HIV (2). Although only 1 case of infection with human HEV3-ra has been identified ( 6 ), the contribution of HEV3-ra to human infection remains uncertain.

\section{The Study}

The French National Reference Center for HEV (Paris, France) analyzed 919 HEV strains obtained from patients

Author affiliations: Centre de Physiopathologie de Toulouse Purpan, Toulouse, France (F. Abravanel, S. Lhomme, H. El Costa, N. Kamar, J. Izopet); Centre Hospitalier Universitaire de Toulouse, Toulouse (F. Abravanel, S. Lhomme, J.-M. Peron, N. Kamar, J. Izopet); Centre Hospitalier Universitaire de Reims, Reims, France (B. Schvartz)

DOI: http://dx.doi.org/10.3201/eid2307.170318 in France infected during 2015-2016. Strains were obtained in hospitals $(90 \%)$ or private medical laboratories $(10 \%)$. A total of $20 \%$ of the strains were obtained from immunocompromised patients.

We detected HEV RNA by using a reverse transcription PCR (RT-PCR) 15189 accredited by the International Organization of Standardization (Geneva, Switzerland) (7). We used a nested RT-PCR to amplify a 345-nt sequence within HEV open reading frame 2 as described (8). To amplify a 365-nt fragment within the $\mathrm{X}$ domain, we performed a nested RT-PCR with outer primers 2600-DOM-X-S (5'-TAYCGRGARACYTGYTCCCG-3') and 3050-DOM-X-AS (5'-ACATCRACATCCCCCTGYTGTATRGA-3') and inner primers 2685-DOM-X-S (5'-AGYTTTGAYGCCTGGG-3') and 3050-DOM-X-AS. Phylogenetic analyses were performed by using neighbor-joining methods, a bootstrap of 1,000 replicates, and MEGA version 7.0 software (http:// www.megasoftware.net/).

Among the 919 patients, 904 were infected with a genotype 3 strain. The subtype infecting $75(8.1 \%)$ of these HEV3-infected patients could not be determined; 302 (32.9\%) patients were infected with clade HEV3-abchij, $522(56.8 \%)$ were infected with clade HEV3-efg, and 5 $(0.5 \%)$ were infected with clade HEV3-ra (GenBank accession nos. KY611812-KY611816) (Figure). All 5 HEV3ra strains had an insertion in the $\mathrm{X}$ domain of the genome (GenBank accession nos. KY825957-KY825961).

All 5 infected patients were men (median age 52 years, range 38-64 years). None of these men had epidemiologic links to HEV or had traveled abroad; 2 lived in northern France, and 3 lived in southern France. One infected patient was immunocompetent and 4 were immunocompromised. The immunocompetent patient had alcoholic cirrhosis and decompensation of his cirrhosis because of the HEV infection. He cleared the HEV infection spontaneously.

All 4 immunocompromised patients were asymptomatic: 2 were solid-organ transplant recipients, and 2 had hematologic malignancies that were being treated with chemotherapy. Levels of alanine aminotransferase for these 4 patients were persistently high, and plasma HEV RNA was still detected 3 months after the initial evaluation, which indicated a chronic infection (9). Three patients were given ribavirin therapy for 3 months. The patients with hematologic malignancies eliminated the virus, but the kidney transplant recipient had a relapse when treatment was stopped. 
The source of infection was unclear because all 5 patients reported they had no direct contact with rabbits. Three patients lived in rural areas, but none recalled any contact with wild or farmed animals. None of them was a hunter. Two patients reported they had eaten rabbit products, but the products were always well-cooked. All patients regularly ate various pork products, and 3 frequently ate raw shellfish (oysters, mussels, or scallops). Two drank tap water, and 3 drank only bottled water. One patient had a vegetable garden (Table).

\section{Conclusions}

HEV3-ra can infect humans and its pathogenesis is similar to that of other HEV3 subtypes. There have been frequent reports of autochthonous HEV3 infections in several industrialized countries, particularly France (10). The HEV3 subtypes responsible are usually similar to those found in swine. These subtypes belong to clades 3-efg and 3-abchij $(11,12)$. Their distribution among 919 symptomatic cases (3c, 26.7\%; 3e, 2\%; and 3f, 47\%) in our study was similar to that reported for asymptomatic blood donors in France (13). However, HEV3-ra strains were not detected in blood donors, probably because of a small sample size.

The rarity of HEV3-ra infections in humans could be the result of fewer persons eating rabbit than pork products (14). In addition, we found that $80 \%$ of the HEV3-ra strains were obtained from immunocompromised patients. However, this population represents only $20 \%$ of the HEV-infected patients characterized by our laboratory. This HEV3 subtype could be less infectious than other subtypes for humans, but additional studies are needed to verify this hypothesis.

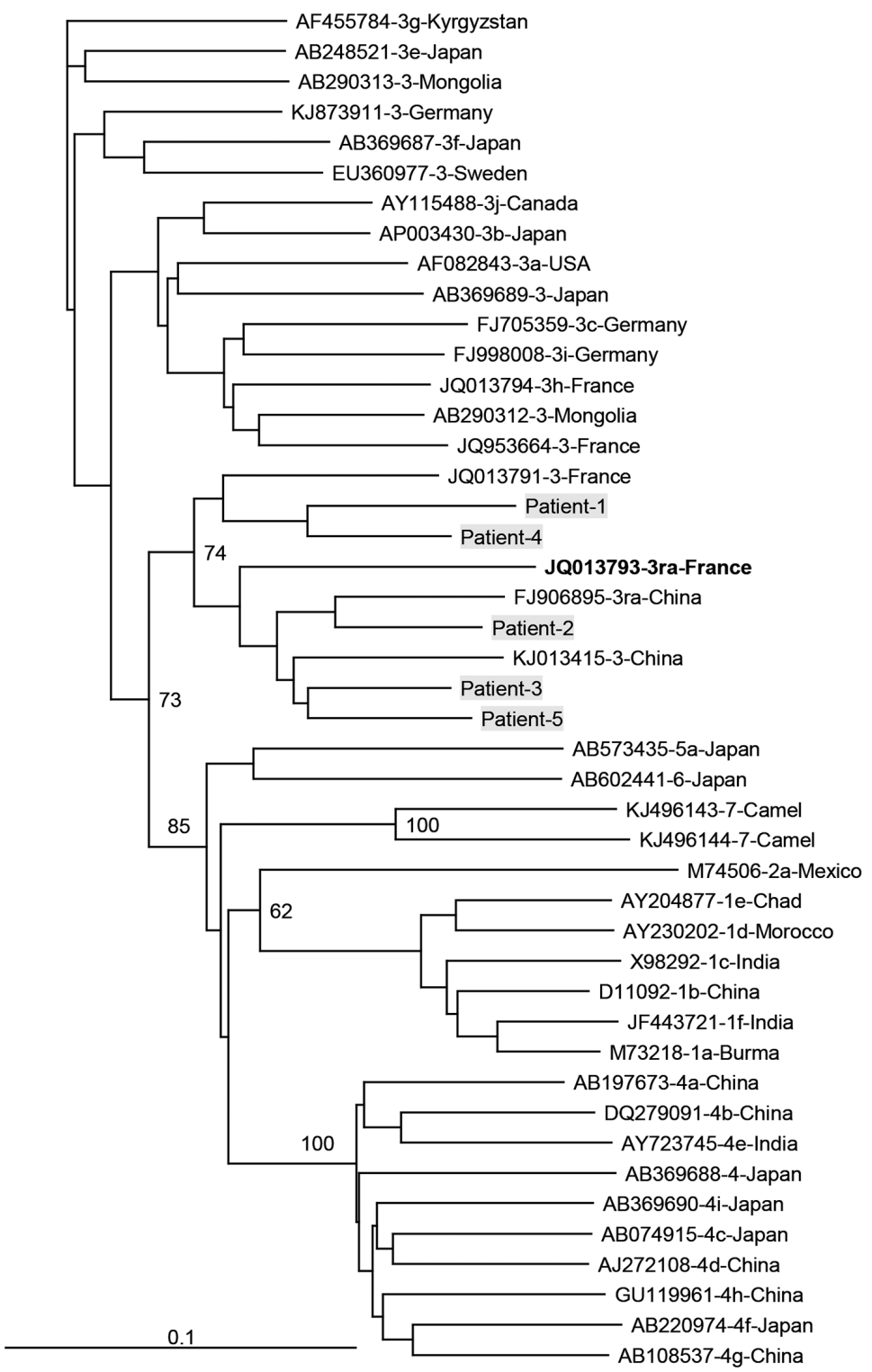

Figure. Phylogenetic tree for a 347-nt sequence within open reading frame 2 of hepatitis $E$ viruses, France. Genetic distances were calculated by using the Kimura 2-parameter method, and the tree was plotted using the by the neighbor-joining method. Values along branches are bootstrap values acquired after 100 replications. Virus sequences obtained from patients in this study (gray shading) were compared with reference sequences of subtypes 3 viruses according to the proposal of Smith et al. (3). GenBank accession numbers, genotypes, and countries of origin are listed. Reference sequence in bold is from a hepatitis $E$ virus genotype 3-ra isolated from a human. Scale bar indicates nucleotide substitutions per site. 
Rabbit Hepatitis E Virus Infections in Humans

Table. Characteristics of 5 men infected with rabbit hepatitis $E$ virus, France

\begin{tabular}{|c|c|c|c|c|c|}
\hline \multirow[b]{2}{*}{ Characteristic } & \multicolumn{5}{|c|}{ Patient } \\
\hline & 1 & 2 & 3 & 4 & 5 \\
\hline Age, y & 52 & 38 & 64 & 50 & 62 \\
\hline Location & Southern (urban) & Northern (urban) & Northern (rural) & Southern (rural) & Southern (rural) \\
\hline Underlying disease or condition & Alcoholic cirrhosis & Kidney transplant & Myeloma & Lymphoma & Heart transplan \\
\hline Symptomatic acute hepatitis E & Yes & No & No & No & No \\
\hline Contact with wild animals & No & No & No & No & No \\
\hline Consumed rabbit & No & Yes & Yes & No & No \\
\hline Consumed pork & Yes & Yes & Yes & Yes & Yes \\
\hline Consumed shellfish & No & No & Yes & Yes & Yes \\
\hline Type of drinking water & Tap & Bottled & Bottled & Bottled & Tap \\
\hline Vegetable garden & No & No & No & Yes & No \\
\hline
\end{tabular}

We could not identify the route by which our patients became infected with HEV3-ra. None had any direct contact with rabbits; 2 had eaten well-cooked rabbit. Data from a recent nationwide study in France suggested that waterborne transmission might play a role in HEV epidemiology (14). This type of transmission might be the way the patients in our study became infected because we have detected HEV3ra in environmental samples (F. Abravanel, unpub. data).

To our knowledge, clinical manifestations associated with HEV3-ra have not been reported. We found that HEV3-ra infections caused severe decompensation in a patient with alcoholic cirrhosis. Chronic infections developed in the 4 immunocompromised patients. Patients in industrialized countries infected with other HEV3 subtypes also showed similar clinical findings (1). We also found that ribavirin had an antiviral effect on HEV3-ra. Ribavirin eliminated the virus in 2 of the 3 patients given this drug. This finding is consistent with that of a multicenter study, which reported that $78 \%$ of persons with chronic HEV3 infections were successfully treated with this drug (15).

Our findings emphasize the zoonotic risk for HEV3-ra and expand the spectrum of potential sources of human infection. The route by which HEV3-ra is transmitted to humans needs to be investigated. Longitudinal study of HEV diversity is also needed to assess trends over time.

Dr. Abravanel is an assistant professor at the Virology Department, Toulouse University Hospital, Toulouse, France. Her primary research interest is genetic variability of hepatitis viruses.

\section{References}

1. Lhomme S, Marion O, Abravanel F, Chapuy-Regaud S, Kamar N, Izopet J. Pathogenesis. Viruses. 2016;8:E212. http://dx.doi.org/ $10.3390 / \mathrm{v} 8080212$

2. Kamar N, Dalton HR, Abravanel F, Izopet J. Hepatitis E virus infection. Clin Microbiol Rev. 2014;27:116-38. http://dx.doi.org/ 10.1128/CMR.00057-13

3. Smith DB, Simmonds P, Izopet J, Oliveira-Filho EF, Ulrich RG, Johne R, et al. Proposed reference sequences for hepatitis E virus subtypes. J Gen Virol. 2016;97:537-42. http://dx.doi.org/10.1099/ jgv.0.000393

4. Lhomme S, Dubois M, Abravanel F, Top S, Bertagnoli S, Guerin JL, et al. Risk of zoonotic transmission of HEV from rabbits. J Clin Virol. 2013;58:357-62. http://dx.doi.org/10.1016/ j.jcv.2013.02.006

5. Caruso C, Modesto P, Prato R, Scaglione FE, De Marco L, Bollo E, et al. Hepatitis E virus: first description in a pet house rabbit. A new transmission route for human? Transbound Emerg Dis. 2015;62:229-32. http://dx.doi.org/10.1111/tbed.12348

6. Izopet J, Dubois M, Bertagnoli S, Lhomme S, Marchandeau S, Boucher S, et al. Hepatitis E virus strains in rabbits and evidence of a closely related strain in humans, France. Emerg Infect Dis. 2012;18:1274-81. http://dx.doi.org/10.3201/eid1808.120057

7. Abravanel F, Sandres-Saune K, Lhomme S, Dubois M, Mansuy JM, Izopet J. Genotype 3 diversity and quantification of hepatitis E virus RNA. J Clin Microbiol. 2012;50:897-902. http://dx.doi.org/10.1128/JCM.05942-11

8. Legrand-Abravanel F, Mansuy JM, Dubois M, Kamar N, Peron JM, Rostaing L, et al. Hepatitis E virus genotype 3 diversity, France. Emerg Infect Dis. 2009;15:110-4. http://dx.doi.org/10.3201/eid1501.080296

9. Kamar N, Rostaing L, Legrand-Abravanel F, Izopet J. How should hepatitis $\mathrm{E}$ virus infection be defined in organ-transplant recipients? Am J Transplant. 2013;13:1935-6. http://dx.doi.org/10.1111/ ajt. 12253

10. Mansuy JM, Abravanel F, Miedouge M, Mengelle C, Merviel C, Dubois M, et al. Acute hepatitis E in south-west France over a 5-year period. J Clin Virol. 2009;44:74-7. http://dx.doi.org/ 10.1016/j.jcv.2008.09.010

11. Bouquet J, Tessé S, Lunazzi A, Eloit M, Rose N, Nicand E, et al. Close similarity between sequences of hepatitis E virus recovered from humans and swine, France, 2008-2009. Emerg Infect Dis. 2011;17:2018-25. http://dx.doi.org/10.3201/eid1711.110616

12. Lhomme S, Abravanel F, Dubois M, Chapuy-Regaud S, Sandres-Saune K, Mansuy JM, et al. Temporal evolution of the distribution of hepatitis E virus genotypes in southwestern France. Infect Genet Evol. 2015;35:50-5. http://dx.doi.org/10.1016/ j.meegid.2015.07.028

13. Gallian P, Lhomme S, Piquet Y, Sauné K, Abravanel F, Assal A, et al. Hepatitis E virus infections in blood donors, France. Emerg Infect Dis. 2014;20:1914-7. http://dx.doi.org/10.3201/ eid2011.140516

14. Mansuy JM, Gallian P, Dimeglio C, Saune K, Arnaud C, Pelletier B, et al. A nationwide survey of hepatitis E viral infection in French blood donors. Hepatology. 2016;63:1145-54. http://dx.doi.org/10.1002/hep.28436

15. Kamar N, Izopet J, Tripon S, Bismuth M, Hillaire S, Dumortier J, et al. Ribavirin for chronic hepatitis $\mathrm{E}$ virus infection in transplant recipients. N Engl J Med. 2014;370:1111-20. http://dx.doi.org/10.1056/NEJMoa1215246

Address for correspondence: Florence Abravanel, Virology Department, Toulouse University Hospital, Institut Fédératif de Biologie, 330 Ave de Grande Bretagne, Toulouse 31059, France; email: abravanel.f@chu-toulouse.fr 